\title{
La funcionalidad de la cláusula penal
}

\author{
Mario Castillo Freyre \\ Felipe Osterling Parodi
}

\section{Consideraciones generales}

Muchas veces, la probanza de la cuantía de los daños y perjuicios no es labor sencilla; no obstante que, en principio, esas dificultades son solucionadas con la posibilidad que otorga la ley de que el juez realice una valoración equitativa de los daños. Pero esa no es la única solución que brinda el derecho. El Código Civil peruano ofrece la posibilidad de que los sujetos de la relación obligacional, en ejercicio de su autonomía privada, establezcan una cláusula penal en el contrato que celebran.

La cláusula penal es la estipulación en un contrato que se refiere a la pena o penalidad convenida para el caso de incumplimiento. Es obvio, por lo demás, que toda vez que las partes pacten una penalidad, lo harán a través de una cláusula en la que se refieran a ella, independientemente de si dicha cláusula solo alude a tal penalidad o si incluye, además, disposiciones de otra naturaleza.

Por otra parte, al tener la cláusula penal carácter accesorio (pues no podría existir sin una obligación cuyo cumplimiento resguarde o garantice), hablar de "obligación con cláusula penal" no resulta errado, en la medida en que se estará haciendo referencia a aquellas relaciones obligatorias que incluyen una penalidad convenida por las partes. 
Más allá de estas consideraciones, la cláusula penal, a grandes rasgos, puede definirse como un pacto anticipado de indemnización. En ella se dispone que si el deudor incumple, tendrá que pagar una indemnización de daños y perjuicios, cuyo monto también se especifica en el pacto.

Cabe subrayar que la cláusula penal, al igual que los daños y perjuicios, puede tener naturaleza moratoria o compensatoria, dependiendo de si con ella se busca indemnizar la mora en el pago o si lo que se pretende indemnizar es el cumplimiento parcial o defectuoso o el incumplimiento definitivo de la obligación.

No hay duda de que la importancia práctica, relevancia teórica y normatividad legal de la cláusula penal determinan que desde antes y después de la promulgación del Código Civil peruano, en julio de 1984, haya merecido el mayor debate académico. Sin embargo, a efectos del presente trabajo, vamos a referirnos únicamente a la funcionalidad de la cláusula penal, puesto que, en esencia, su definición pone de relieve, de alguna manera, las distintas funciones que cumple esa modalidad obligacional.

\section{Funcionalidad de la cláusula penal}

Luego de realizar un análisis sobre los conceptos generales que engloba esta figura, es preciso tener en cuenta que las definiciones formuladas por diversos autores ponen de relieve, de alguna manera, las distintas funciones que cumpliría la cláusula penal. Destaca en especial aquella contenida en el numeral 1341 del Código Civil (1984), que establece lo siguiente:

El pacto por el que se acuerda que, en caso de incumplimiento, uno de los contratantes queda obligado al pago de una penalidad, tiene el efecto de limitar el resarcimiento a esta prestación y a que se devuelva la contraprestación, si la hubiere; salvo que se haya estipulado la indemnización del daño ulterior. En este último caso, el deudor deberá pagar el íntegro de la penalidad, pero esta se computa como parte de los daños y perjuicios si fueran mayores.

A continuación, se analizarán las funciones más importantes que cumple esta figura. 


\subsection{Función indemnizatoria de la cláusula penal}

Como señala Kemelmajer (1981), para cierto sector de la doctrina, la cláusula penal está exclusivamente destinada a limitar el resarcimiento de los daños que puedan originarse por el incumplimiento de la obligación. Opera a la manera de tope convencional y anticipado de los daños, como liquidación de su cuantía. Este autor precisa que la indemnizatoria sería la función principal que desempeñaría la cláusula penal (Kemelmajer, 1981, pp. 6-7). Este criterio es compartido por Emiliani Román (1980, pp. 294-296) y Martínez (1997, pp. 161-162), quienes señalan que la función indemnizatoria que cumpliría la cláusula penal es la predominante en el derecho moderno, porque mediante su fijación las partes determinan con antelación el monto que deberá pagar el deudor en caso de incumplimiento. En opinión nuestra, la función indemnizatoria de la cláusula penal es, sin duda, relevante.

Es verdad que la cláusula penal tiene una evidente e insustituible función indemnizatoria. Sin embargo, apreciamos que dicha función debe verse en sí misma separada de la idea de evitar la probanza ulterior de los daños y perjuicios ocasionados por el deudor ante el incumplimiento de sus obligaciones contractuales, o de limitar los daños y perjuicios que eventualmente se causen en el futuro.

Como consecuencia de lo expresado, la función indemnizatoria debe ser apreciada única y exclusivamente como el avalúo anticipado de los daños y perjuicios que el incumplimiento pudiera causar. Esto equivale a decir que, en teoría, es la penalidad convenida -y no los daños y perjuicios realmente causados- la que deberá considerarse como monto indemnizatorio por pagar.

Cabe destacar que la penalidad pactada por las partes no siempre representará el monto de lo que ellas juzguen como eventuales daños y perjuicios, pues resulta evidente que, aun cuando se estime como tales una cantidad determinada, podría pactarse -con la finalidad de cumplir otras funciones propias de la cláusula penal- un monto mucho mayor o incluso sustancialmente menor que el previsto para efectos del incumplimiento.

Por su parte, Martínez (1997), según el artículo 1341 del Código Civil peruano, señala:

La cláusula penal cumpliría una función exclusivamente indemnizatoria y no compulsiva, pues afirma que esta última función sólo 
tiene lugar en aquellos ordenamientos que se han inclinado por la inmutabilidad de la cláusula penal.

Esto quiere decir, por el hecho de que luego de pactado su monto no puedan discutirlo judicialmente, principio que no ha sido consagrado por nuestro ordenamiento, según el artículo 1346 del Código Civil.

Agrega que este precepto, por el contrario, señala la mutabilidad parcial de la cláusula penal, es decir, que la pena puede ser reducida por el juez cuando a solicitud del deudor resulte manifiestamente excesiva. (p. 163)

Debemos subrayar que los sistemas jurídicos en los que se recoge la mutabilidad de la pena -entre los cuales se encuentra el Código Civil peruano de 1984- relativizan notoriamente la función indemnizatoria de la cláusula penal, aunque no la llegan a eliminar, tal como apreciaremos en su oportunidad.

Así pues, por lo expuesto, consideramos que el Código Civil peruano de 1984, en el artículo 1341, define los rasgos característicos de la cláusula penal, pues alude claramente a su finalidad indemnizatoria, sin descartar otras funciones que, como veremos, también puede cumplir.

Dicho razonamiento se sustenta, adicionalmente, por lo expresado en la propia Exposición de Motivos del Código Civil, cuando se señala que este sistema "está destinado a asegurar al acreedor que ve incumplida la obligación por dolo o por culpa del deudor, la cobranza del íntegro de la penalidad, que constituye el resarcimiento fijado anteladamente" (Osterling, 1988, p. 583).

\subsubsection{Pautas de la función indemnizatoria de la cláusula penal}

Kemelmajer (1981) señala tres pautas de las cuales surge la función indemnizatoria como predominante de la cláusula penal:

En primer término, se refiere al hecho de que la pena entraría en lugar de la indemnización de perjuicios e intereses.

En segundo lugar, cabría la posibilidad de reducir la cláusula penal, lo que vendría a ser un efecto de su carácter indemnizatorio. Dicha disminución sólo será aplicable en aquellos sistemas donde la ley faculte al juez a reducir el monto de la penalidad establecida por las partes, ya sea de oficio o a solicitud del deudor (propio del Derecho peruano). 
Queda claro que en los sistemas de inmutabilidad de la cláusula penal no podrá disminuirse el monto de la penalidad convenida.

Finalmente, muchas veces la cláusula penal se tornaría insuficiente y es entonces evidente que ella no cumplirá ninguna presión psicológica sobre el deudor. (pp. 9-10)

Cabe señalar que no todos los ordenamientos jurídicos prevén la posibilidad de aumento de la penalidad cuando los daños y perjuicios verdaderamente causados fueren mayores al monto de la cláusula penal convenida. Ello solo resulta posible en los sistemas que han optado por la mutabilidad de la cláusula penal: "En el caso concreto del Perú, la posibilidad de que el monto de la penalidad aumente sólo se contempla para el supuesto en que las partes hubieren convenido la indemnización del daño ulterior" (Código Civil peruano, 1984, art. 1341).

\subsubsection{Posición que asume el carácter no forzoso indemnizatorio de la cláusula penal}

Algunos autores sostienen que, aunque de ordinario la cláusula penal cumple función resarcitoria, no es forzoso que tenga tal carácter. En este sentido, Llambías (1983) afirma:

Los deberes de conducta que no imputan obligaciones strictu sensu, por no ser de contenido patrimonial (no susceptibles de apreciación pecuniaria), pueden ser fortalecidos en su cumplimiento mediante la estipulación de cláusulas penales; ahí no se puede decir que tal cláusula tenga función resarcitoria, puesto que, por hipótesis, la persona en cuyo favor se ha comprometido la conducta esperada, no experimenta daño patrimonial alguno por la frustración de esa expectativa. (pp. 104-105)

Cita como ejemplo el caso en que dos amigos conciertan hacer un viaje de placer conjunto en determinada fecha y convienen en que uno de ellos pagará al otro una suma de dinero si por su culpa hiciera fracasar la excursión; allí -precisa el autor- la cláusula penal asume el papel de una pena privada y no tiene carácter indemnizatorio.

Pensamos que el ejemplo empleado por Llambías (1983) "para ilustrar su posición, en el sentido de que no es forzoso el carácter indemnizatorio de la cláusula penal, no resulta del todo apropiado, fundamentalmente porque se podría dudar de que la 'obligación' asu- 
mida sea, precisamente, una obligación" (pp. 104-105). Tal concertación podríamos entenderla como parte de un trato coloquial entre los dos amigos materia del ejemplo. Y, como sabemos, los tratos sociales de esta índole generan compromisos que no constituyen, jurídicamente hablando, obligaciones.

Ahora bien, dentro del propio ejemplo, también resultaría discutible considerar que la penalidad convenida sea, propiamente, una cláusula penal, tanto por el contexto en el que se inscribe como por ser cuestionable que una situación de esta naturaleza corresponda, en la realidad de los hechos, a un caso idóneo.

Nosotros pensamos que la función indemnizatoria sí resulta esencial a toda cláusula penal, independientemente de la obligación principal de que se trate y con prescindencia del sistema de mutabilidad o inmutabilidad que rija en el medio jurídico correspondiente. En pocas palabras, si una estipulación no tiene por finalidad indemnizar, jamás podría ser llamada cláusula penal.

\subsection{Función compulsiva de la cláusula penal}

Borda (1986) señala que "la cláusula penal es un medio de compulsar a los deudores a cumplir con sus obligaciones, ante la amenaza de una sanción, normalmente, más gravosa que la obligación contraída, exponiendo al deudor a un grave peligro para el caso de incumplimiento" (p. 196).

Respecto al carácter compulsivo de la cláusula penal, Llambías (1983) también sostiene que "ella adopta esta función, pues agrega un estímulo que mueve psicológicamente al deudor a cumplir con la prestación principal para eludir la pena que suele ser hasta gravosa" (p. 419). Igualmente, Savigni manifiesta que "la cláusula penal incita al cumplimiento por el temor de la pena, con lo cual viene a reforzar la sanción del contrato principal" (como se citó en Llambías, 1983, p. 419).

Debemos señalar que cuando se dice que la cláusula penal constituye una garantía para el cumplimiento de la obligación, el término garantía debería emplearse entrecomillado, en la medida en que la cláusula penal no constituye una garantía propiamente dicha de la obligación. No olvidemos que dentro de nuestro ordenamiento jurídico las garantías pueden ser personales o reales.

La cláusula penal no es una garantía en sentido estricto, pues ni amplía ni refuerza el patrimonio respecto al cual el acreedor podrá 
intentar hacer efectivo su crédito, ya que la penalidad deberá ser pagada, de ser el caso, por el propio deudor. Así, ante el eventual incumplimiento de la obligación principal por el deudor, si el acreedor decidiera hacer efectiva la penalidad convenida, nada cobraría ante la insolvencia del deudor.

En tal sentido, no podríamos afirmar que la cláusula penal constituye una garantía propiamente dicha. Lo único que podemos decir válidamente es que la cláusula penal, en cierta forma, refuerza o garantiza de mejor manera los intereses del acreedor en ver satisfecho su crédito o, subsidiariamente, en cobrar la penalidad estipulada.

No siendo una obligación de objeto plural, la obligación pactada con cláusula penal otorga una posibilidad adicional al acreedor afectado por el incumplimiento del deudor, para -mientras dicho deudor sea solventesatisfacer sus intereses con el cumplimiento, voluntario o forzoso, de la prestación accesoria. En este punto cabría formular una interrogante: ¿la cláusula penal constituye un estímulo al cumplimiento regular de la obligación o un estímulo a no dejar de cumplir?

Esta pregunta, que parecería ser un juego de palabras, no es tal, pues la cláusula penal no induce al deudor a que cumpla. Las motivaciones del cumplimiento se derivan, en el terreno jurídico, de la propia naturaleza de la obligación y, en el terreno moral, del cumplimiento de la palabra empeñada. Sin embargo, la cláusula penal, si su cuantía o magnitud es determinada como suficientemente severa, hará que el deudor pueda disuadirse de incumplir con la obligación, dado que las consecuencias del incumplimiento podrían ser mucho más severas que las del cumplimiento regular.

Es claro que la cláusula penal no le da mayor fuerza obligatoria a una relación jurídica, pues tal situación se presenta por el solo hecho de haber nacido una obligación en virtud de una norma legal o de la voluntad humana. En otras palabras, asumiendo un sentido coloquial, podríamos afirmar que una obligación no es más obligación que otra por el hecho de haberse pactado en ella una penalidad.

\subsection{Función compulsiva e indemnizatoria de la cláusula penal}

Algunos autores sostienen que la cláusula penal tiene una función ambivalente, es decir, que cumple a la vez una función compulsiva e indemnizatoria (Llambías, 1983; Dávila, 1992). En este sentido, Giorgi (1909) manifiesta: 
Cuando se pacta una cláusula penal se añade al contrato una convención accesoria, por la que el deudor que deja de cumplir su promesa principal, queda tenido a dar alguna cosa al acreedor para compensarlo de la pérdida que produce la falta de ejecución del contrato.

La finalidad de la cláusula penal es reforzar el vínculo contractual y establecer una indemnización convencional. (pp. 462-466)

Por nuestra parte, al afirmar la posibilidad de que la cláusula penal pueda cumplir por lo menos una, pero incluso más de una función, consideramos que ella puede tener una función ambivalente, siendo a la vez compulsiva e indemnizatoria. Tal concepto nos parece acertado. Sin embargo, también nos da pie para afirmar que no se trata solo de una dualidad, sino de una eventual pluralidad de funciones de la cláusula penal.

\subsection{Función punitiva de la cláusula penal}

Cierto sector de la doctrina pone de relieve el carácter punitivo de la cláusula penal. Así, Díez-Picazo (1979) la considera como "una sanción convencionalmente establecida del incumplimiento o del cumplimiento defectuoso. De ahí su nombre de pena y de multa convencional" (p. 160).

Nosotros creemos acertado considerar el carácter punitivo de la cláusula penal. Sin embargo, lo hacemos cuidadosamente, pues la punición puede ser entendida como sanción justa o como sanción injusta o desproporcionada. Consideramos que en ambos casos la cláusula penal tendría función punitiva y, más allá de los sistemas de la mutabilidad o inmutabilidad de la institución, en los dos supuestos se admite el pacto de las penalidades que correspondan -en la realidad de los hechos- al monto de los daños y perjuicios causados o a montos que superen tales daños y perjuicios.

Afirmamos que la finalidad punitiva de la cláusula penal siempre estará presente, sea en un caso o en el otro, pero se apreciará con mayor nitidez su carácter sancionatorio cuando ella guarde desproporción, por exceso, con la prestación incumplida. Por lo demás, resulta evidente que no podríamos hablar de una función punitiva en aquellas cláusulas penales diminutas, pactadas fundamentalmente con el objeto de limitar la responsabilidad del deudor ante el incumplimiento de sus obligaciones, porque aquí no habría sanción alguna. 


\subsection{Función de simplificación probatoria de la cláusula penal}

Se puede observar en la cláusula penal un pacto relativo a la carga de la prueba del daño, además de su carácter compulsivo o indemnizatorio. En este orden de ideas, el acreedor podría exigir el cumplimiento de la cláusula penal sin probar la existencia misma del daño, ni demostrar el quantum del perjuicio. Sin embargo, ella no se deberá si el deudor prueba que no se ha producido daño. Se trata, en suma, de una reversión de la carga probatoria.

No obstante, Kemelmajer (1981) sostiene que "la función de simplificación probatoria no puede admitirse sin reservas en aquellos ordenamientos en los cuales el deudor no se libera, acreditando que el daño no se ha producido, como es el caso del Derecho argentino y del peruano" (p. 13).

El artículo 1343 del Código Civil peruano (1984) señala:

La cláusula penal sólo podrá exigirse cuando el incumplimiento se deba a causa imputable al deudor, es decir, cuando el deudor haya incumplido totalmente su obligación o la haya cumplido irregularmente por dolo, culpa inexcusable o culpa leve, salvo que mediara pacto en contrario. Por eso no se exige, en principio, probar los daños y perjuicios sufridos.

Resulta evidente que la cláusula penal, dentro de sus funciones, tiene una de simplificación probatoria, en la medida en que si las partes efectúan un avalúo convencional y anticipado de los eventuales y futuros daños y perjuicios que podría ocasionar el incumplimiento de la obligación o su cumplimiento irregular, tal avalúo tendría por objeto evitar el debate en un proceso judicial acerca de su existencia y cuantía.

Pensamos que dentro del terreno teórico, y sin entrar al análisis de la legislación nacional, la función de simplificación probatoria reviste gran utilidad, en tanto y en cuanto la probanza del monto de los daños y perjuicios constituye uno de los temas de mayor dificultad en todo proceso judicial, en el que con frecuencia puede probarse la efectiva producción de dichos daños y perjuicios, pero no se llega a acreditar el monto o cuantía exacta de estos.

El caso más notorio en que podría presentarse este problema ocurre cuando los daños y perjuicios comprenden el daño moral, que, según parecer absolutamente mayoritario de la doctrina, resulta ser de más difícil probanza en lo que respecta a su exacta magnitud. 


\subsection{Función resolutoria de la cláusula penal}

De las diversas funciones que la doctrina suele asignar a la cláusula penal, la resolutoria es una de las más discutibles. Es claro, para quienes están en desacuerdo con este principio, que la ejecución de la cláusula penal no implica la resolución del contrato, dado que la cláusula penal y la resolución contractual son dos figuras jurídicas distintas. Por ello, corresponde analizar si la cláusula penal, cuando se hace efectiva, conduce a la resolución del contrato, fuente de la obligación principal.

Para tal efecto, precisamos distinguir si se trata de una cláusula penal compensatoria o moratoria. Dentro de los supuestos susceptibles de presentarse en las cláusulas penales compensatorias, estaría aquel en el cual la obligación incumplida garantizada con la cláusula penal fuese la única que tenía que ejecutar el deudor o la más importante de todas.

Como se sabe, la cláusula penal compensatoria tiene por finalidad sustituir la prestación incumplida. En tal sentido, si el acreedor perjudicado decidiera ejecutar la penalidad pactada, es evidente que ya no podría subsistir la obligación principal; o, dicho en otras palabras, el deudor no podría continuar obligado a cumplir la prestación principal.

En tal orden de ideas, si en los hechos ese deudor ya no está obligado a cumplir con la prestación principal, tal situación configuraría un caso muy similar al de la resolución de los contratos, pues la resolución tiene por finalidad dejar sin efecto un contrato por la existencia de un vicio sobreviniente al tiempo de su celebración. En este caso, analógicamente, dicho vicio se configuraría por el incumplimiento de la obligación principal del deudor. Entonces, si la obligación principal ya no se debe, porque el acreedor perjudicado prefirió sustituirla por la penalidad pactada, el contrato seguiría existiendo, por ser válido, pero ya no surtiría efectos ni sería capaz de generarlos.

En tal sentido, dicha situación podría describirse como un acto de efectos similares a los de la resolución, pero sin ser, en estricto, un caso de resolución contractual. Esta última afirmación obedece a que el Código Civil prescribe con claridad los supuestos de resolución contractual, que pueden tener carácter judicial o extrajudicial de conformidad con lo dispuesto por sus artículos 1428, 1429 y 1430. Y entendemos, por lo tanto, que si el acreedor perjudicado no acudiera a alguno de estos mecanismos, no podríamos hablar de una resolución contractual propiamente dicha. 
Cabe hacer notar, sin embargo, que consideramos que si la prestación incumplida garantizada con la cláusula penal fuese la de mayor importancia o una de importancia sustancial, o incluso la única asumida por el deudor, sería factible pensar que la cláusula penal tendría una finalidad resolutoria, debido a que el acreedor, en muchos casos, carecería de interés en que el deudor siguiese ostentando jurídicamente tal condición.

La conclusión es distinta, sin duda, cuando la cláusula penal es moratoria. Aquí no se resuelve contrato alguno y el deudor, además de la penalidad por mora, deberá cumplir la prestación principal.

\subsection{Función de pena de arrepentimiento de la cláusula penal}

Si bien es cierto que la función de arrepentimiento no es considerada por la doctrina mayoritaria como propia de la cláusula penal, ella podría presentarse en ciertos casos. Concretamente, recordamos el caso de las arras penitenciales o de retractación, en los artículos 1480-1483 del Código Civil peruano (1984), propias de los contratos preparatorios:

Si un deudor decidiera incumplir su obligación, y ésta estuviese respaldada por una cláusula penal, en principio el acreedor tendría derecho a exigir al deudor el cumplimiento de la prestación principal en especie, vale decir, la ejecución de la prestación debida. Lo expresado se presentará fundamentalmente en las obligaciones de dar, en que es posible la ejecución forzosa de la prestación principal.

Sin embargo, en las obligaciones de hacer y de no hacer, en las que no se pueda exigir el cumplimiento forzoso de la obligación (porque para ello el acreedor tendría que emplear violencia contra la persona del deudor), el acreedor deberá resignarse al incumplimiento de la prestación debida, pudiendo únicamente recurrir a la vía indemnizatoria que, en estos casos, estaría respaldada por la indemnización anticipada contenida en la cláusula penal.

\section{Conclusiones en torno a la funcionalidad de la cláusula penal en el marco de la legislación peruana}

Consideramos que resulta necesario referirnos a cada una de las funciones que en teoría cumple la cláusula penal y confrontarlas con el régimen legal peruano. 
En cuanto a la función compulsiva de la cláusula penal, como hemos mencionado oportunamente, esta estará presente como un elemento que refuerce el cumplimiento de las obligaciones sin constituir, en estricto, una garantía en términos jurídicos.

Dentro del régimen legal peruano, tal como lo establecen los artículos 1341 y 1342 del Código Civil peruano (1984), "la función compulsiva de la cláusula penal puede ser tanto compensatoria como moratoria". Si fuera compulsiva y compensatoria, estaría destinada a sustituir la prestación incumplida por la penalidad pactada (perdiendo el deudor que incumple el derecho a la contraprestación, si la hubiere). Por otra parte, la función compulsiva moratoria estará circunscrita a indemnizar la mora en el pago.

Desde el punto de vista de la función compulsiva de la cláusula penal, si ella fuere compensatoria, el carácter compulsivo estaría dado en conducir a que el deudor no incumpla con la prestación debida y a que no la cumpla de manera parcial o defectuosa. En otras palabras, la cláusula penal compensatoria buscará que el deudor no deje de cumplir de manera íntegra e idónea. En cambio, la cláusula penal moratoria tendrá como función compulsiva el hacer que el deudor no deje de cumplir en tiempo oportuno, pues se vería expuesto a incurrir en mora y a que se desencadene la sanción correspondiente.

Resulta claro que la norma contenida en el artículo 1346 del Código Civil peruano (1984) -la cual establece que el juez, a solicitud del deudor, puede reducir equitativamente la pena cuando sea manifiestamente excesiva- relativiza de alguna manera la función compulsiva de la cláusula penal. Esto es así porque, al haber adoptado el Código Civil peruano (1984) el sistema de la mutabilidad relativa, en la práctica ocurren numerosos casos de deudores que, siendo conscientes de la posibilidad legal de alegar el exceso de la penalidad, deciden no cumplir o cumplir tardíamente, teniendo abierta la posibilidad para reclamar judicialmente la reducción de la pena.

De otro lado, no hay que olvidar que la parte final del artículo 1346 del Código Civil peruano (1984) permite al deudor solicitar al juez que proceda a reducir equitativamente la pena cuando la obligación hubiese sido en parte o irregularmente cumplida. Si bien esta situación no es discutida en el plano teórico por la doctrina, sí constituye un factor que resta atribuciones compulsivas a la cláusula penal pactada. 
En adición a lo expresado, debemos recordar que la reducción de la cláusula penal viene siendo interpretada por los tribunales peruanos de manera subjetiva, vale decir, con prescindencia de los medios probatorios que, teóricamente, deberían aportar los deudores incumplientes para demostrar que la penalidad tenía carácter excesivo. Esta situación ha conducido a que el tema se deje al arbitrio subjetivo de los tribunales de justicia, además de que el deudor que alega el exceso de la pena cuenta con la "comodidad" de que no está obligado, necesariamente, a probar la existencia de dicho exceso.

Será evidente, por lo demás, que en la mayoría de los casos el acreedor se encontrará en una situación incómoda, pues de no haber pactado la indemnización por daño ulterior el proceso judicial iniciado por el deudor se reduciría a que este último probase un monto menor a la pena pactada por concepto de indemnización por daños y perjuicios; o, en todo caso, que tal deudor nada pruebe y deje a criterio de los jueces el efectuar una valoración equitativa, quienes pueden reducir el monto de la penalidad, si la consideraran excesiva.

En lo que respecta a la función indemnizatoria de la cláusula penal, dentro del marco legal peruano es indudable que esta finalidad está presente, de conformidad con lo establecido por el artículo 1341 del Código Civil (1984). Asimismo, cabe enfatizar que la cláusula penal siempre cumplirá una función indemnizatoria, tanto cuando ella pudiera corresponder, en su monto, a la cuantía de los daños y perjuicios verdaderamente causados, como cuando resultare diminuta o excesiva.

Si la cláusula penal fuere diminuta y no se hubiere pactado la indemnización del daño ulterior, resulta evidente que el acreedor no podría demandar el aumento de la pena estipulada, y aquello que cobre indemnizará parcialmente los daños y perjuicios causados. En tal sentido, por más que la indemnización de los daños y perjuicios fuera solo parcial, resulta indudable que la cláusula penal seguiría teniendo función indemnizatoria.

En el otro extremo, si la cláusula penal fuese excesiva en comparación con los daños y perjuicios causados, pero el deudor, por los motivos que fuere, no solicitara su reducción, dicho deudor tendría que pagarla en su integridad. En este caso, si bien es cierto que el deudor pagará una indemnización mayor que los daños y perjuicios realmente causados, esta indudablemente también cumplirá una función indemnizatoria. La tendrá en la parte correspondiente a los daños y perjuicios realmente 
causados (lo que resulta obvio), pero también en lo que respecta a los daños no causados, pues la cláusula penal constituye un pacto anticipado de indemnización ante un eventual incumplimiento del deudor.

En adición, si el deudor no reclama ante los tribunales la eventual reducción de la penalidad convenida, tal renuncia constituye, en nuestro concepto, una ratificación tácita de que los términos pactados como penalidad constituyen fiel reflejo de aquellos que posteriormente se causaron.

Por otra parte, y teniendo en cuenta que la tercera función que la doctrina asigna a la cláusula penal es la punitiva o sancionatoria, resulta evidente que una penalidad tendría función punitiva en la medida en que el monto de esta exceda la cuantía real de los daños y perjuicios ocasionados, pero que, adicionalmente, se llegue a pagar por el deudor incumpliente.

Ahora bien, si tenemos en consideración las facultades que el Código Civil peruano (1984) otorga al deudor para solicitar judicialmente la reducción de la penalidad, por estimarla manifiestamente excesiva, y si el deudor lograse que esta se redujera, ello nos demostraría que el sistema adoptado por el Código Civil puede conducir a que la cláusula penal carezca de función punitiva.

Por otra parte, la función punitiva podría mantenerse vigente en la medida en que el deudor, a pesar de que los daños y perjuicios sean menores que la penalidad pactada, no reclame su reducción. En estos casos, se debería entender que dicho deudor estaría aceptando tácitamente ser sancionado con la penalidad pactada. Pero debemos reconocer que este último supuesto resultaría, en la práctica, sumamente extraño, y que en el Perú la función punitiva o sancionadora de la cláusula penal se encuentra relativizada.

Asimismo, hemos mencionado que la doctrina asigna a la cláusula penal una función de simplificación probatoria. En efecto, como sabemos, se critica al Código Civil de 1984 porque la posibilidad de modificar el monto de la penalidad desnaturalizaría la institución que estamos analizando, pues si el deudor puede solicitar su disminución cuando fuera manifiestamente excesiva, y si se faculta al acreedor para pedir el aumento de la penalidad cuando fuese diminuta (en caso de pacto de daño ulterior), las partes tendrían que ingresar, necesariamente, a la probanza de los daños y perjuicios, lo cual significa incurrir en lo que se quiso evitar mediante la estipulación de la cláusula penal. 
Dicho en otros términos, ¿qué sentido tendría pactar una penalidad si, una vez verificada la inejecución, las partes se verían irremediablemente sumergidas en un engorroso proceso en el que tendrían que demostrar que los daños derivados del incumplimiento son en verdad mayores o menores -dependiendo del caso- que el monto de la cláusula penal?

Cabe señalar que este problema no se soluciona atribuyendo a quien solicite la modificación de la pena la carga de probar que los daños infringidos sean mayores o menores que la penalidad pactada. En efecto, en los supuestos en que se solicite la reducción del monto de la pena, el deudor tendrá la carga de probar que los daños derivados de la inejecución son menores a la suma pactada. Sin embargo, un acreedor diligente, consciente de la posibilidad de que se reduzca el monto de la pena, de todas maneras entrará al tema probatorio, aun cuando esta carga no le sea impuesta legalmente, a efectos de demostrar que los daños sufridos coinciden con el monto establecido en la cláusula penal o que, incluso, son superiores a dicho monto.

Lo propio ocurre en el supuesto en que se solicite el aumento de la penalidad, habida cuenta de que, aun cuando el acreedor tenga que demostrar que los daños resultantes de la inejecución se encuentran por encima de la pena pactada, el deudor -qué duda cabe- buscará demostrar que la cláusula penal no solamente es suficiente, sino, inclusive, excesiva, solicitando su reducción proporcional. En ambos casos, la probanza de los daños y perjuicios es inevitable.

Por otra parte, un sector de la doctrina señala que la cláusula penal tiene una función resolutoria. Sobre el particular, simplemente diremos que las ideas allí vertidas resultan de plena aplicación al régimen legal impuesto por el Código Civil peruano de 1984. Luego, otro sector de la doctrina señala que la cláusula penal tiene la función de pena acumulativa.

En el caso del Código Civil peruano (1984), y salvo que se hubiese pactado algo distinto, solo podría cumplir función de pena acumulativa, en la medida en que se tratara de una cláusula penal moratoria, ya que el cobro de esta resultaría independiente del cobro de la prestación principal. En su artículo 1342 señala expresamente este concepto, precepto que establece que "cuando la cláusula penal se estipula para el caso de mora o en seguridad de un pacto determinado, el acreedor tiene derecho para exigir, además de la penalidad, el cumplimiento de la obligación". Pero, independientemente del texto citado, para nosotros es claro que ello fluye de la propia naturaleza de la institución. 
Por un lado, si la cláusula penal fuese compensatoria, y a pesar de que la citada norma no lo diga, se desprende de la naturaleza de la cláusula penal el que esta no pueda acumularse a la prestación in natura, prohibición que, en cambio, sí es establecida expresamente por el artículo 1383 del Código Civil italiano de 1942.

De otro lado, recordemos que un sector de la doctrina sostiene que la cláusula penal cumple la función de pena de arrepentimiento. En principio, la cláusula penal no tiene como objeto primordial constituir una pena de arrepentimiento, pues dicha función se encuentra históricamente centrada en las arras penitenciales o de retractación, tema regulado por los artículos 1480 a 1483 del Código Civil peruano de 1984.

Como percibirá el lector, si bien es cierto que al analizar el tema en términos generales le hemos negado a la cláusula penal, como una de sus funciones primordiales, la de ser una pena de arrepentimiento, hemos admitido que la puede tener con carácter subsidiario, en la medida en que, tratándose de una cláusula penal compensatoria, el acreedor perjudicado no pueda exigir el cumplimiento in natura de la prestación incumplida, sea porque esta devino en imposible o porque para su ejecución se tendría que emplear violencia contra la persona del deudor.

Esta última situación se planteará, fundamentalmente, en aquellas obligaciones de hacer y de no hacer cuyo cumplimiento se encuentre respaldado por una cláusula penal. Para tal efecto, podemos citar lo dispuesto por los artículos 1150 y 1158 del Código Civil peruano (1984), referidos a las obligaciones de hacer y de no hacer, respectivamente, cuando expresan que su incumplimiento por culpa del deudor faculta al acreedor a optar, entre otras medidas, por exigir la ejecución forzada del hecho o abstención prometidos, a no ser que sea necesario para ello emplear violencia contra la persona del deudor.

Finalmente, cabe señalar que la doctrina asigna a la cláusula penal una función moratoria. Sobre el particular, nos limitaremos a expresar que las doctrinas generales sobre el tema resultan de entera aplicación al derecho peruano, en especial lo establecido en el artículo 1342 del Código Civil de 1984.

\section{Conclusiones}

De lo expuesto en este análisis, se infiere que existe concordancia entre la teoría general de la funcionalidad de la cláusula penal y su aplicación 
dentro del marco normativo del Código Civil peruano (1984), cumpliendo esta figura una función polivalente.

Todo ello, incluso, no obstante la presencia de la primera parte del artículo 1346, norma que permite al deudor solicitar al juez la reducción equitativa de la pena, cuando ella sea manifiestamente excesiva. Sin embargo, debemos dejar constancia de que sí creemos que dicha norma atenta contra algunos aspectos de la funcionalidad de la cláusula penal.

\section{Referencias}

Borda, G. (1986). Tratado de derecho civil. Obligaciones (tomo I, 8. ${ }^{\mathrm{a}}$ ed.). Buenos Aires, Argentina: Perrot.

Código Civil (Italia). Decreto Real 262. (4 de abril de 1942). Recuperado de http://www.jus.unitn.it/cardozo/obiter_dictum/codciv/ Codciv.htm

Código Civil (Perú). Decreto Legislativo 295. (25 de julio de 1984). Recuperado de http://spij.minjus.gob.pe/CLP/contenidos. dll?f=templates\&fn=default-codcivil.htm\&vid=Ciclope:CLPdemo

Dávila, J. (1992). La obligación con cláusula penal. Madrid, España: Montecorvo.

Díez-Picazo, L. (1979). Fundamentos del derecho civil patrimonial (tomo I). Madrid, España: Tecnos.

Emiliani Román, R. (1980). Conferencias de obligaciones. Bogotá, Colombia: Temis.

Giorgi, G. (1909). Teoría de las obligaciones en el derecho moderno (volumen IV). Expuesta conforme a la doctrina y a la jurisprudencia italiana, francesa, alemana, etc. (Traducida de la sétima edición italiana y anotada con arreglo a las legislaciones española y americanas por la redacción de la Revista General de la Legislación y Jurisprudencia). Madrid, España: Imprenta de la Revista de Legislación.

Kemelmajer, A. (1981). La cláusula penal. Buenos Aires, Argentina: Ediciones Depalma.

Llambías, J. J. (1983). Tratado de derecho civil. Obligaciones (tomo I, 4. ${ }^{a}$ ed.). Buenos Aires, Argentina: Perrot.

Martínez, E. (1997). Ensayos de derecho civil I. Lima, Perú: Editorial San Marcos. 
Osterling, F. (1988). Las Obligaciones. En Biblioteca para leer el Código Civil (volumen VI). Lima, Perú: Fondo Editorial de la Pontificia Universidad Católica del Perú.

Osterling, F., y Castillo, M. (2014). Tratado de derecho de las obligaciones (volumen VI, 2. a ed.). Lima, Perú: Thomson Reuters. 